\title{
Prognostic value of subclinical myocardial necrosis using high-sensitivity cardiac troponin T in patients with prediabetes
}

Marco Witkowski ${ }^{1}$, Yuping Wu' ${ }^{2}$, Stanley L. Hazen ${ }^{1,3}$ and W. H. Wilson Tang ${ }^{1,3^{*}}$ (D)

\begin{abstract}
Background: Risk stratification of patients with prediabetes is an unmet clinical need. Here, we examine the utility of subclinical myocardial necrosis assessed by high-sensitivity cardiac troponin T (hs-cTnT) in predicting health outcomes in stable subjects with prediabetes.

Methods: hs-cTnT was analyzed by a high-sensitivity assay (Roche 5th generation) in 2631 stable subjects with prediabetes (HbA1c 5.7-6.4\% or fasting glucose 100-125 mg/dL without previous diagnosis of diabetes or glucose-lowering therapy) who underwent elective coronary angiography for cardiac evaluation, and followed for major adverse cardiac events (MACE; death, myocardial infarction, stroke) over 3 years and all-cause mortality over 5 years.

Results: In our study cohort, hs-cTnT was highly prevalent with a median level of $13 \mathrm{ng} / \mathrm{L}$ (interquartile range 8.2$21.6 \mathrm{ng} / \mathrm{L}$ ). Hs-cTnT was independently associated with incident MACE at 3 years (Q4 vs. Q1 adjusted hazard ratio (HR) $2.42[95 \% \mathrm{Cl} 1.69-3.46], \mathrm{P}<0.001$ ) and 5-year mortality (adjusted HR 3.8 [95\% Cl 2.55-5.67], $\mathrm{P}<0.001$ ). This association remained significant in all subsets after adjustment for traditional risk factors and multiple factors known to increase hs-cTnT levels. Moreover, hs-cTnT independently predicted event risk in primary prevention subjects ( $n=557$, HR 5.46 [95\% Cl 1.50-19.89), p < 0.01) for MACE; HR 9.53 [95\% Cl 2.08-43.73] for all-cause mortality) and secondary prevention subjects ( $n=2074$, HR 1.86 [95\% Cl 1.31-2.66], $P<0.001$ for MACE; and 2.7 [95\% Cl 1.79-4.08), $P<0.001$ for all-cause mortality).
\end{abstract}

Conclusions: In stable prediabetic subjects, the presence of subclinical myocardial necrosis as detected by hs-cTnT portends heightened long-term adverse cardiovascular event risk. Hs-cTnT levels may help to stratify risk and improve clinical decision making in patients with prediabetes.

Trial registration ClinicalTrials.gov Identifier: NCT00590200.

Keywords: Prediabetes, Cardiac troponin T, Prognosis

\section{Introduction}

Prediabetes, defined as glycemic concentrations above normal but lower than diabetes thresholds, has emerged as a new category of abnormal glycemic control. Besides

\footnotetext{
*Correspondence: tangw@ccf.org

${ }^{3}$ Department of Cardiovascular Medicine, Heart, Vascular and Thoracic Institute, Cleveland Clinic, 9500 Euclid Avenue, Desk J3-4, Cleveland, OH 44195, USA

Full list of author information is available at the end of the article
}

impaired fasting glucose (IFG) or impaired glucose tolerance (IGT), the American Diabetes Association recently introduced glycated hemoglobin A1c (HbA1c) 5.7-6.4\% to define prediabetes [1]. Population-based survey data estimates that more than one third of the United States population ( $>84$ million people) can be considered "prediabetic" based on IFG or HbA1c [2]. While the wellknown association between diabetes and macrovascular complications justifies aggressive medical interventions, original author(s) and the source, provide a link to the Creative Commons licence, and indicate if changes were made. The images or other third party material in this article are included in the article's Creative Commons licence, unless indicated otherwise in a credit line to the material. If material is not included in the article's Creative Commons licence and your intended use is not permitted by statutory regulation or exceeds the permitted use, you will need to obtain permission directly from the copyright holder. To view a copy of this licence, visit http://creativecommons.org/licenses/by/4.0/. The Creative Commons Public Domain Dedication waiver (http://creativeco mmons.org/publicdomain/zero/1.0/) applies to the data made available in this article, unless otherwise stated in a credit line to the data. 
cardiovascular risk stratification for individuals with dysglycemia in the pre-diabetic range has proven difficult and is complicated by different classifications and cutoffs for prediabetes [3]. In fact, many studies report that prediabetes does not portend the same increase in cardiovascular disease (CVD) risk as seen in diabetes and association of prediabetes with cardiovascular complications are inconsistent throughout multiple studies both in the general population [4-8] as well as secondary prevention subjects [9-11]. Therefore, a test that helps to identify those individuals that are at increased cardiac risk amongst prediabetic patients would be very helpful.

Since the availability of high-sensitivity cardiac troponin $\mathrm{T}$ (hs-cTnT) assays, the prognostic utility of subclinical myocardial necrosis (SMN) has gained growing appreciation in their ability to predict adverse long-term cardiovascular risk in stable cardiovascular patients [12, 13]. We and others have previously shown that hs-cTnT is associated with major adverse cardiac events (MACE) in patients with diabetes [14] and that prediabetes is independently associated with incident of SMN and CVD risk in community-based populations $[6,15]$. We therefore hypothesize that SMN, as detected by hs-cTnT, may portend poor prognosis in a stable cohort of prediabetic subjects (with no clinical or laboratory evidence for an acute coronary syndrome at enrollment) undergoing elective diagnostic cardiac evaluations. Herein we examined the clinical prognostic utility of hs-cTnT in both primary and secondary prevention subjects as a biomarker to identify prediabetic subjects at increased cardiovascular risk and thus appropriate for more aggressive preventive efforts.

\section{Methods}

\section{Study population}

The Cleveland Clinic GeneBank Study is a large, singlecenter, prospective cohort study with a thoroughly characterized collection of clinical data and longitudinal outcomes in stable patients undergoing elective diagnostic angiography because of suspected CAD or progression of known CAD at the Cleveland Clinic between 2001 and 2007 (detailed inclusion and exclusion criteria can be found at ClinicalTrials.gov Identifier: NCT00590200). All participants gave written informed consent to a protocol that was approved by the Cleveland Clinic Institutional Review Board. This analysis included 2,631 stable cardiac patients without acute coronary syndrome (cardiac troponin $\mathrm{I} \leq 0.3 \mathrm{ng} / \mathrm{mL}$ ) and with a diagnosis of prediabetes, defined as no history of diabetes mellitus or use of glucose-lowering drugs, and with HbA1c levels between 5.7 and $6.4 \%$ or fasting plasma glucose levels between 100 and $125 \mathrm{mg} / \mathrm{dL}$.

Primary prevention was defined as those without CVD, which included either coronary artery disease (CAD, any clinical history of myocardial infarction, coronary revascularization [such as percutaneous coronary intervention, coronary artery bypass surgery], or angiographic evidence of significant stenosis $[\geq 50 \%]$ in 1 or more major coronary arteries) or peripheral artery disease (non-coronary arterial territories including extracranial carotid artery stenosis, upper extremity artery stenosis, renal artery stenosis, and lower extremity arterial diseases, while diseases of the aorta were not included). Secondary prevention was defined as those with evidence for CVD. Estimated glomerular filtration rate (eGFR) was calculated via CKD-EPI equation [16]. Subjects were followed for 3 years following enrollment to determine the occurrence of MACE, defined as all-cause mortality, nonfatal myocardial infarction, or nonfatal stroke. Subjects were also followed for 5 years for all-cause mortality. All endpoints in our cohort were collected by in-person prospective follow-up including letter solicitation and reply cards, chart review, and direct contact by study staff by follow-up telephone interviews, and were adjudicated and confirmed by source documentation over the ensuing 3 years after enrollment. All-cause mortality was determined by chart review confirmed by Social Security Death Index 5 years after enrollment.

\section{Subclinical myocardial necrosis}

During the time of the cardiac catheterization procedure, all blood samples were collected after arterial sheath access had been obtained and prior to diagnostic catheterization or treatment, including heparin administration. High-sensitivity cardiac troponin T levels were measured on a Roche Cobas E411 with 5th generation research assay (Roche laboratories, Indianapolis IN) at CAP/CLIA-approved research laboratory. The limit of detection was $3 \mathrm{ng} / \mathrm{L}$ and there were no values measured below this level in this cohort. The 99th percentile cutoff was $14 \mathrm{ng} / \mathrm{L}$ with an average coefficient of variation $<10 \%$ at that level. High-sensitivity C-reactive protein (hsCRP) and lipid profiles were also measured by the same platform.

\section{Statistical analysis}

Continuous variables were summarized as mean \pm standard deviation if normally distributed and median with interquartile range [IQR] if non-normally distributed. Cox proportional hazard analysis was used to assess the clinical risks associated with hs-cTnT levels as stratified in group quartiles (Q). Adjustments were made for age, gender, systolic blood pressure, low-density lipoprotein cholesterol, high-density lipoprotein cholesterol, former/current cigarette smoking and eGFR to predict the 3-year MACE risks or all-cause mortality at 5 years. In additional analyses, we included CVD, hsCRP, HbA1c or 
left ventricular ejection fraction (LVEF) in addition to the above-mentioned risk factors into the adjustment. We confirmed that both the proportionality hazards and linearity assumptions were met. We used Cochran-Armitage and Jonckheere-Terpstra tests of trend to compare baseline characteristics across increasing quartiles of hs-cTnT for categorical and continuous variables, respectively. Analyses were performed with $\mathrm{R}$ version 4.0.2 and $\mathrm{P}<0.05$ was considered statistically significant.

\section{Results}

Baseline characteristics of the study population are shown in Table 1. As expected, the majority of subjects (71\%) demonstrated evidence of clinically significant coronary artery disease $(\geq 50 \%$ stenosis at any vessel, with increasing prevalence across hs-cTnT quartiles, see Additional file 1: Table S1), with $15.5 \%$ subsequently underwent coronary revascularization within 30 days following coronary angiography. The average estimated glomerular filtration rate (eGFR) was $83.8 \mathrm{~mL} / \mathrm{min} / 1.73 \mathrm{~m}^{2}$. In this patient cohort without history or evidence of acute coronary syndrome, hs-cTnT was detectable in all subjects with a median hs-cTnT level of $13 \mathrm{ng} / \mathrm{L}$ (IQR 8.2, $21.6 \mathrm{ng} / \mathrm{L})$.

\section{Subclinical myocardial necrosis and major adverse cardiac event risk among prediabetic patients}

Figure 1 shows the Kaplan-Meier analysis for eventfree survival in patients stratified by hs-cTnT quartiles. Increasing hs-cTnT levels were associated with an incremental increase in event risk for 3-year MACE and 5-year all-cause mortality in the entire cohort (Fig. 1A, B, $\log$ rank $\mathrm{P}<0.001)$ especially when raised above median level (Q2).

Table 1 Baseline characteristics of study population

\begin{tabular}{|c|c|c|c|c|c|c|}
\hline Variables & $\begin{array}{l}\text { All subjects } \\
(n=2631)\end{array}$ & $\begin{array}{l}\text { Quartile } 1 \\
(n=658)\end{array}$ & $\begin{array}{l}\text { Quartile } 2 \\
(n=653)\end{array}$ & $\begin{array}{l}\text { Quartile } 3 \\
(n=661)\end{array}$ & $\begin{array}{l}\text { Quartile } 4 \\
(n=659)\end{array}$ & $P$ value for trend \\
\hline hs-cTnT range (ng/L) & & $<8.2$ & $8.2-13$ & $13-21.6$ & $\geq 21.6$ & \\
\hline Age (years) & $65 \pm 11.2$ & $59.9 \pm 10$ & $63.4 \pm 10.5$ & $68.3 \pm 10$ & $68.4 \pm 11.9$ & $<0.001$ \\
\hline Male (\%) & 72.4 & 66.3 & 75.2 & 75.2 & 73.1 & 0.001 \\
\hline $\mathrm{BMI}\left(\mathrm{kg} / \mathrm{m}^{2}\right)$ & $28.4(25.4-31.9)$ & $28.6(25.8-32.7)$ & $28.7(25.8-32)$ & $28.1(25.4-31.3)$ & $27.7(24.9-31.6)$ & 0.001 \\
\hline HbA1c (\%) & $5.8(5.5-6.0)$ & $5.7(5.5-6.0)$ & $5.8(5.5-6.0)$ & $5.8(5.4-6.0)$ & $5.8(5.5-6.0)$ & 0.094 \\
\hline$(\mathrm{mmol} / \mathrm{mol})$ & $39.9(36.6-42.1)$ & $38.8(36.6-42.1)$ & $39.9(36.6-42.1)$ & $39.9(35.5-42.1)$ & $39.9(36.6-42.1)$ & \\
\hline $\begin{array}{l}\text { Fasting blood glu- } \\
\text { cose (mg/dL) }\end{array}$ & $103.2(95.2-110)$ & 103 (94.9-110) & $102.9(94.7-110)$ & $103.6(97.2-110)$ & $103.8(95.1-110)$ & 0.438 \\
\hline \multicolumn{7}{|l|}{ Risk factors } \\
\hline Hypertension (\%) & 71 & 64 & 68 & 76 & 77 & $<0.001$ \\
\hline $\begin{array}{c}\text { Former/current } \\
\text { smokers (\%) }\end{array}$ & 67 & 65 & 70 & 67 & 66.5 & 0.394 \\
\hline CVD (\%) & 78.8 & 67.6 & 72.9 & 84.3 & 90.4 & $<0.001$ \\
\hline CAD (\%) & 74.8 & 63.1 & 70 & 78.3 & 87.8 & $<0.001$ \\
\hline PAD (\%) & 24.7 & 17.2 & 19.3 & 32.1 & 30 & $<0.001$ \\
\hline \multicolumn{7}{|l|}{ Laboratory data } \\
\hline LDLc (mg/dL) & $97(79-119)$ & $100(82-122)$ & $98(81-120)$ & $95.5(77-116)$ & $96(79-117)$ & 0.032 \\
\hline HDLc (mg/dL) & $37(31-46)$ & $37(31-46)$ & $37(31-45)$ & $38(31-47)$ & $36(30-45)$ & 0.106 \\
\hline $\mathrm{TG}(\mathrm{mg} / \mathrm{dL})$ & $118(85-169)$ & $124(86-179)$ & $117(87-172)$ & $111(83-157)$ & $121(88-173)$ & 0.004 \\
\hline hsCRP (mg/L) & $2.3(1.0-5.3)$ & $1.8(0.8-3.9)$ & $1.9(0.9-3.6)$ & $2.0(0.9-4.4)$ & $5.3(1.9-13.5)$ & $<0.001$ \\
\hline $\begin{array}{l}\text { eGFR }(\mathrm{mL} / \mathrm{min} \text { per } \\
\left.1.73 \mathrm{~m}^{2}\right)\end{array}$ & 83.7 (68.6-94.3) & $90.3(79.7-98.4)$ & $85.2(73.7-95.6)$ & $78.9(65.0-91.0)$ & $76.2(58.5-91.0)$ & $<0.001$ \\
\hline \multicolumn{7}{|l|}{ Medications } \\
\hline ACEi/ARB (\%) & 46.6 & 37.5 & 46.4 & 50.5 & 52 & $<0.001$ \\
\hline$\beta$-Blockers (\%) & 60.6 & 58.7 & 61.7 & 62.5 & 59.6 & 0.456 \\
\hline Statins (\%) & 57.7 & 55.9 & 60 & 58.5 & 56.3 & 0.388 \\
\hline Aspirin (\%) & 73 & 74.8 & 74.1 & 72.3 & 70.9 & 0.37 \\
\hline
\end{tabular}

Continuous data are presented as mean \pm standard deviation or median (interquartile range), categorical variables are presented as $\%$

$A C E i$ angiotensin-converting enzyme inhibitor, $A R B$ angiotensin receptor blockers, $B M I$ body mass index, $C A D$ coronary artery disease, $P A D$ peripheral artery disease, eGFR estimated glomerular filtration rate, $\mathrm{HbA} 1 \mathrm{c}$ glycated hemoglobin, $H D L c$ high-density lipoprotein cholesterol, $h s C R P$ high-sensitivity $C$-reactive protein, $h s$ - $c T h T$ high-sensitivity cardiac troponin T, LDL low-density lipoprotein cholesterol, MACE major adverse cardiac events, TG triglycerides 
A
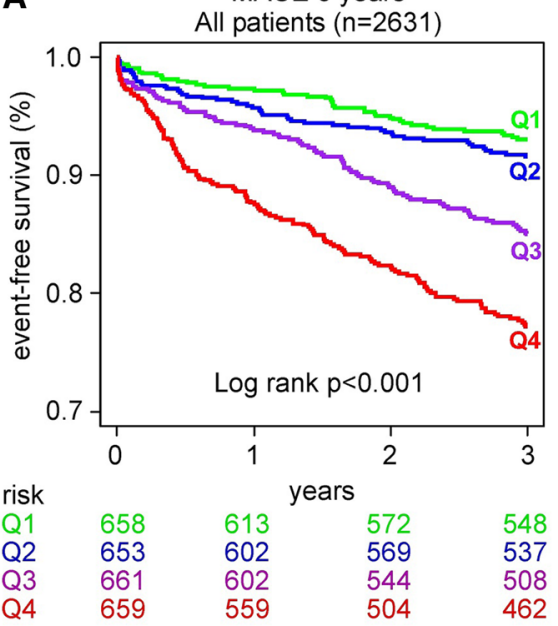

C

MACE 3 years

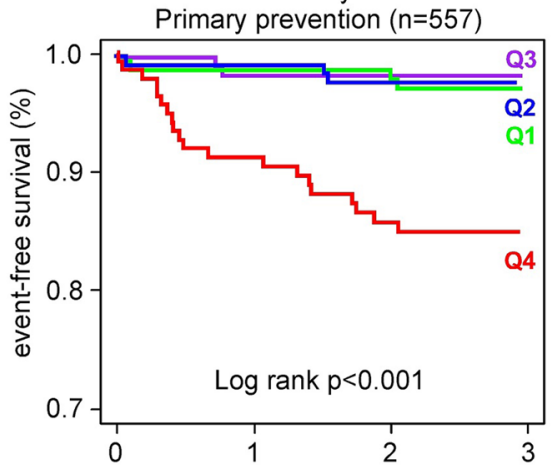

No. at risk

\begin{tabular}{lllll} 
risk & \multicolumn{4}{c}{ years } \\
Q1 & 137 & 130 & 125 & 121 \\
Q2 & 141 & 135 & 129 & 127 \\
Q3 & 138 & 128 & 120 & 114 \\
Q4 & 141 & 122 & 109 & 106
\end{tabular}

MACE 3 years

E Secondary prevention $(n=2074)$

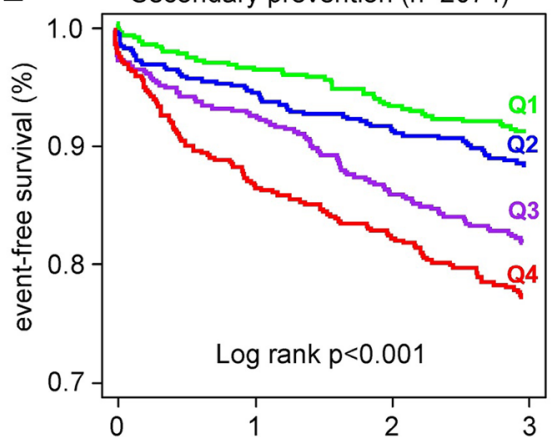

No. at risk

$\begin{array}{ll}\text { Q1 } & 519 \\ \text { Q2 } & 518 \\ \text { Q3 } & 518 \\ \text { Q4 } & 519\end{array}$

years

\begin{tabular}{lll}
\multicolumn{2}{c}{ years } \\
479 & 442 & 421 \\
475 & 447 & 415 \\
469 & 417 & 388 \\
438 & 400 & 363
\end{tabular}

B Death 5 years

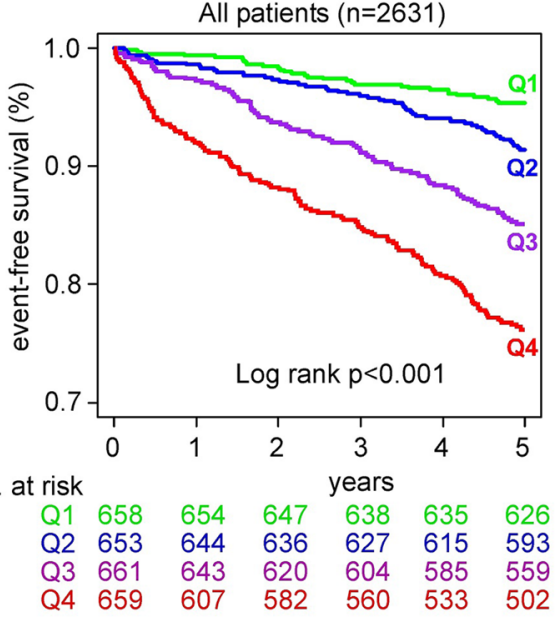

D Death 5 years

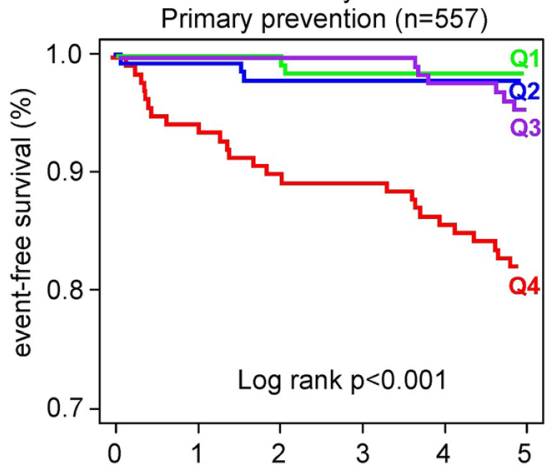

No. at risk years

$\begin{array}{lllllll}\text { Q1 } & 137 & 137 & 137 & 135 & 135 & 134 \\ \text { Q2 } & 141 & 140 & 138 & 138 & 138 & 137 \\ \text { Q3 } & 138 & 138 & 138 & 138 & 135 & 128 \\ \text { Q4 } & 141 & 133 & 127 & 126 & 122 & 115\end{array}$

. Death 5 years

F Secondary prevention $(n=2074)$

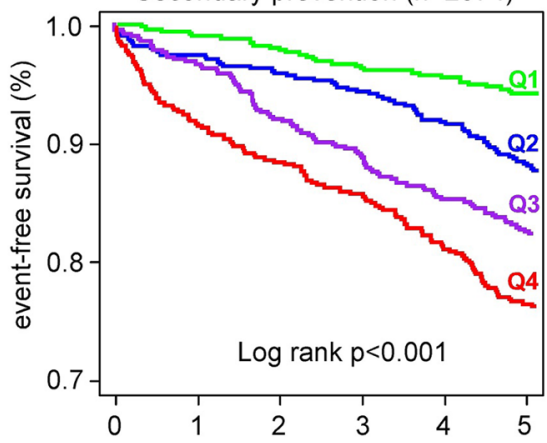

No. at risk years

$\begin{array}{lllllll}\text { Q1 } & 519 & 514 & 507 & 499 & 496 & 489 \\ \text { Q2 } & 518 & 509 & 501 & 492 & 479 & 458 \\ \text { Q3 } & 518 & 501 & 477 & 458 & 442 & 423 \\ \text { Q4 } & 519 & 476 & 460 & 443 & 421 & 396\end{array}$

Fig. 1 Kaplan-Meier estimates and the risk of incident major adverse cardiac events (MACE, defined as myocardial infarction, stroke, or death) as well as all-cause mortality over follow-up periods of 3 and 5 years, respectively, stratified by quartile of hs-cTnT levels. Shown is the analysis for all patients $(\mathbf{A}, \mathbf{B})$, primary prevention subjects $(\mathbf{C}, \mathbf{D})$ and secondary prevention subjects $(\mathbf{E}, \mathbf{F})$ 
In the subset with primary prevention subjects, those in the highest hs-cTnT ( $\geq 14.4 \mathrm{ng} / \mathrm{L})$ also had a significant higher risk for 3-year MACE and 5-year all-cause mortality (Fig. $1 C, D, \log$ rank $\mathrm{P}<0.001$ ), while in secondary prevention patients, hs-cTnT levels above median levels $(\geq 14.2 \mathrm{ng} / \mathrm{L})$ portended an incremental risk for 3-year MACE and 5-year all-cause mortality (Fig. 1E, F, $\log \operatorname{rank} \mathrm{P}<0.001)$.

Figure 2 demonstrates unadjusted and adjusted Cox proportional hazard ratios (HR) for incident development of MACE in 3 years. Prediabetic patients with hscTnT levels in Quartile 3 (hs-cTnT 13-21.6 ng/L) and Quartile 4 (hs-cTnT $\geq 21.6 \mathrm{ng} / \mathrm{L}$ ) had a 2.25-fold (HR 2.25 [95\% CI 1.57-3.22), $\mathrm{P}<0.001]$ ) and 3.63-fold (HR 3.63 [95\% CI 2.58-5.10], $\mathrm{P}<0.001)$ increased risk for MACE, respectively. These increased risks for MACE remained significant after adjusting for traditional risk factors $(\mathrm{Q} 3$ vs. Q1: adjusted HR 1.65 [95\% CI 1.14-2.39], P < 0.01; Q4 vs. Q1: adjusted HR 2.42 (1.69-3.46), $\mathrm{P}<0.001$ ) (Fig. 2A). In the subset analyses, higher hs-cTnT levels were associated with a fivefold increase in MACE (Q4 vs Q1: adjusted HR 5.46 [95\% 1.50-19.89], $\mathrm{P}<0.01$ ) in the primary prevention cohort (Fig. 2C) and a 1.9-fold increase in MACE (Q4 vs. Q1: adjusted HR 1.86 [95\% CI 1.312.66], $\mathrm{P}<0.001$, Fig. 2E) in the secondary prevention cohort following adjustments for traditional risk factors.

\section{Subclinical myocardial necrosis and mortality risk among prediabetic patients}

Prediabetic patients with elevated hs-cTnT levels had higher 5-year mortality (Q2 vs. Q1: HR 1.88 [95\% CI 1.21-2.94]; $\mathrm{P}<0.01$; Q3 vs. Q1: HR 3.40 [95\% CI 2.265.12]; $\mathrm{P}<0.001$; Q4 vs. Q1: HR 5.85 [95\% CI 3.95-8.64], $\mathrm{P}<0.001)$. This association remained significant after adjustments for traditional risk factors: Q3 vs Q1: adjusted HR 2.19 [95\% CI 1.44-3.34], P < 0.001; Q4 vs. Q1: adjusted HR 3.37 [95\% CI 2.25-5.05], P<0.001) (Fig. 2B). Heightened mortality risk remained significant after adjustment in the primary prevention cohort $(\mathrm{Q} 4$ vs. Q1: adjusted HR 9.53 [95\% CI 2.08-43.73], $\mathrm{P}<0.01$, Fig. 2D) and secondary prevention cohort (Q4 vs. Q1: adjusted HR 2.70 [95\% CI 1.79-4.08], P < 0.001, Fig. 2F).

When further adjusting for hsCRP, use of statins or angiotensin converting enzyme inhibitors, HbA1c or LVEF, higher hs-cTnT levels remained significantly associated with increased 3-year MACE and 5-year death in the entire cohort, as well as primary (Q4 vs. Q1-3) and secondary prevention subjects (Additional file 1: Tables S2-S4). We also performed additional analysis in the subset of patients who did not undergo coronary revascularization within 30 days following angiography, and observed similar trends, even when adjusting for traditional and above-mentioned CVD risk factors as well as degree and extent of disease burden (Additional file 1: Table S5). These sensitivity analyses highlight the independent prognostic value of hs-cTnT in this prediabetic population.

\section{Event risk among different subgroups}

Adverse event and mortality risks were similar among multiple clinical subgroups in the entire cohort (Fig. 3) including preserved and impaired kidney function. Using hs-cTnT as a continuous variable, cubic spline analyses showed a virtually linear increase in HR for MACE and 5-year all-cause mortality as hs-cTnT rises in the prediabetic population (Fig. 4). Interestingly, there was no correlation between the levels of hs-cTnT and either fasting glucose or HbA1c in our cohort $(r=0.03, P=0.191$ and $\mathrm{r}=0.03, \mathrm{P}=0.146$, respectively, for Spearman correlation).

\section{Discussion}

We presented one of the largest reported cohort of patients with prediabetes undergoing elective diagnostic invasive cardiac evaluation stratified by SMN to assess cardiovascular outcomes. Plasma levels of hs-cTnT were incrementally associated with the incident risk for MACE as well as all-cause mortality after extensive multivariate adjustment for CVD risk factors and conditions known to increase plasma hs-cTnT levels. Notably, in both primary prevention and secondary prevention subjects, hs-cTnT provided significant prognostic value. Our study demonstrates that SMN is prevalent in patients with prediabetes undergoing elective diagnostic cardiac evaluation, with almost half of our study cohort above the 99th upper limit of normal. Our findings imply that quantification of plasma hs-cTnT may convey additional prognostic value for the risk stratification of individuals with prediabetes in the presence of cardiovascular risk factors.

There is ample evidence that diabetes confers CVD event risk through factors involving glycemic variability [17], inflammation [18-20], platelet dysfunction [21, 22] and a pro-thrombotic state [23-25]. Yet, the picture in the prediabetic range is less clear. While some previous studies in the general population provided evidence that prediabetes defined by fasting glucose, HbA1c or oral glucose tolerance test (OGTT) may be associated with higher risk for CVD and mortality [26, 27] many other studies did not report an association between prediabetes and CVD complications [4, 5, 7]. Risk stratification of these subjects is critical to prevent cardiovascular complications. However, the inconsistent association of prediabetes with cardiovascular events sustains an ongoing debate about prediabetes being a "dubious diagnosis" that results in unnecessary medical interventions and stresses the healthcare system 


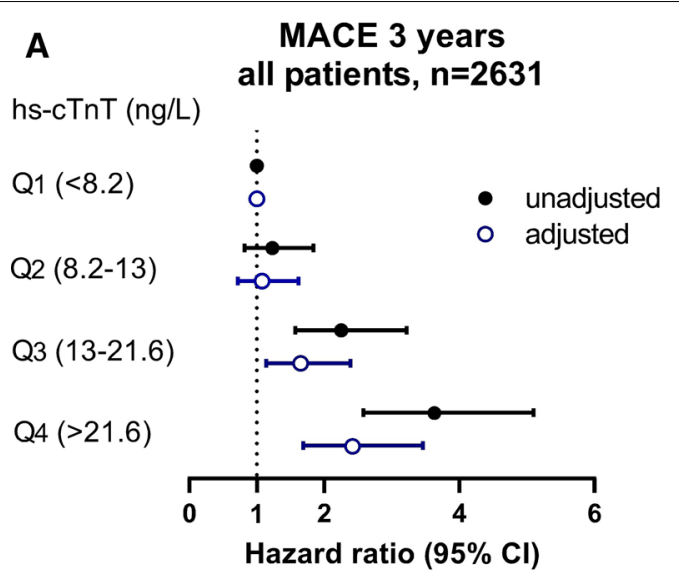

B

Death 5 years

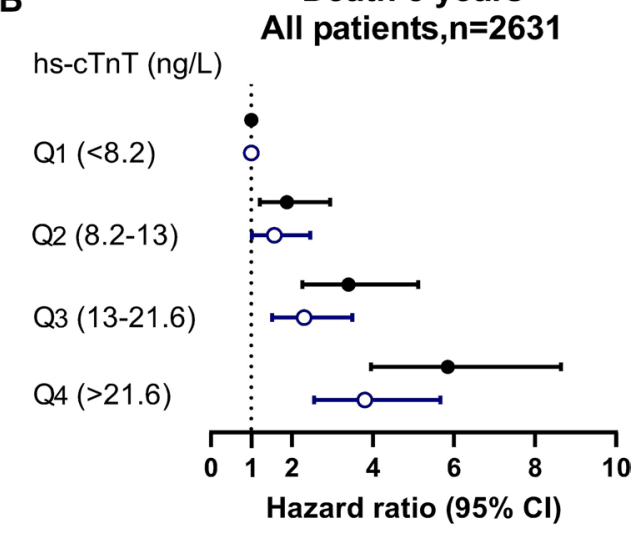

D

Death 5 years

MACE 3 years
Primary prevention, $n=557$

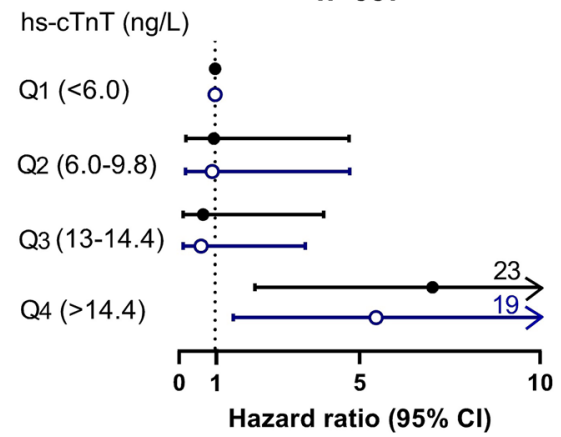

E Seconday prevention,

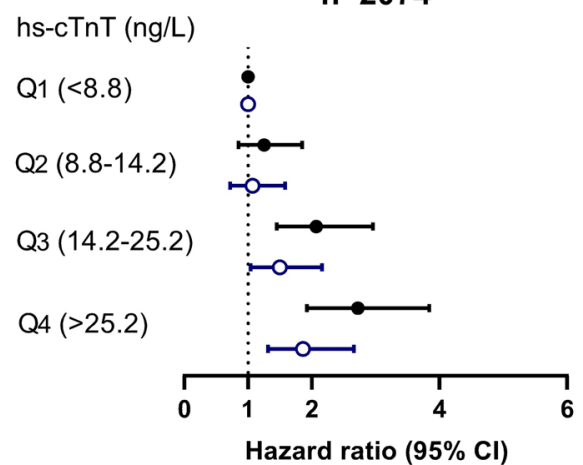

Primary prevention, $n=557$

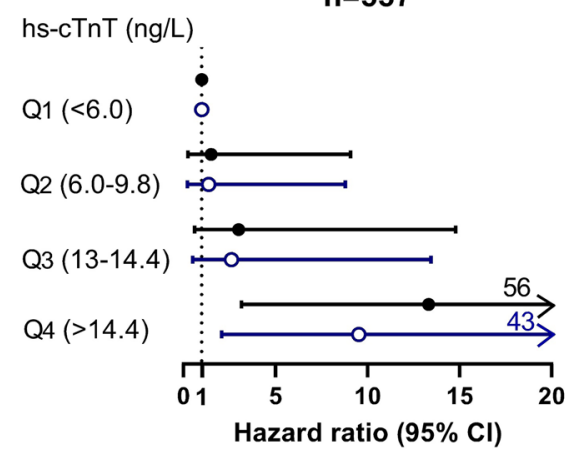

F

Death 5 years Secondary prevention, $n=2074$

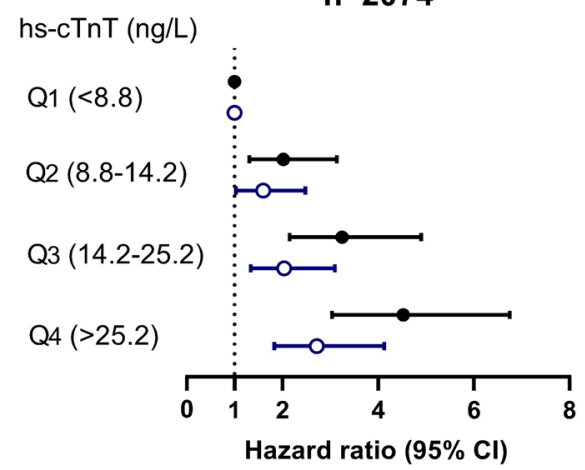

Fig. 2 Forest plots indicating the risks of incident MACE at 3 years and death after 5 years ranked by quartiles of hs-cTnT levels. The multivariable Cox model for hazard ratio included adjustments for age, sex, systolic blood pressure, low density lipoprotein cholesterol, high density lipoprotein cholesterol, smoking and estimated glomerular filtration rate. The 5-95\% confidence interval is indicated by line length. Shown is the analysis for all patients $(\mathbf{A}, \mathbf{B})$, primary prevention subjects $(\mathbf{C}, \mathbf{D})$ and secondary prevention subjects $(\mathbf{E}, \mathbf{F})$

[28, 29]. Our study provides evidence that extend of SMN represents a biomarker that is useful to identify prediabetic patients at risk to avoid unnecessary care and improve outcomes. Although the consequence of myocardial necrosis can be determined via other imaging-based techniques such as late gadolinium enhancement by cardiac magnetic resonance for myocardial fibrosis [30, 31], measurement of hs-cTnT is readily 
A

\section{A HR for 3-year MACE \\ $n=2631$}

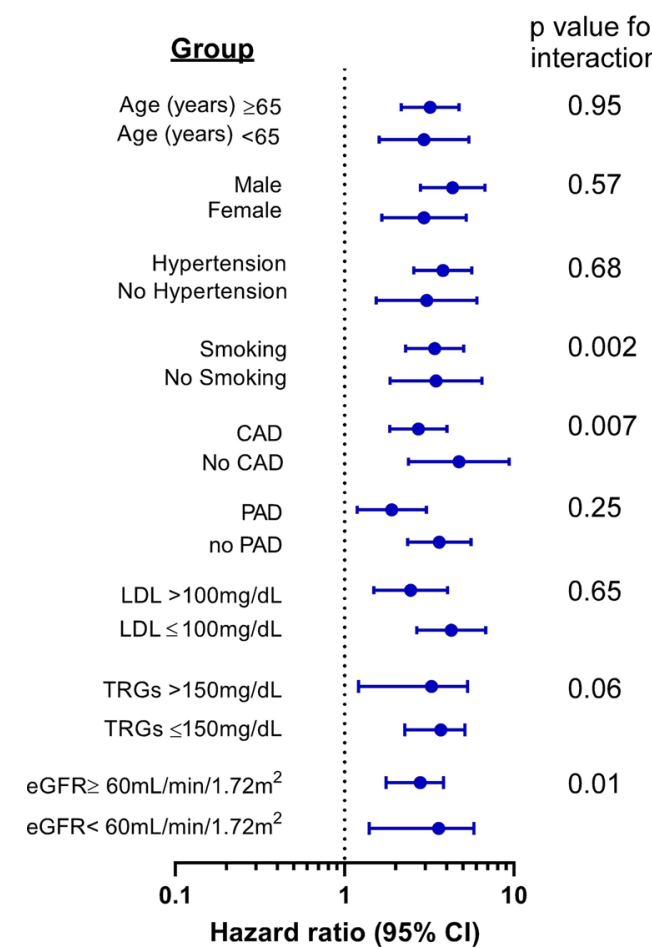

B

\section{HR for 5-year death $\mathrm{n}=2631$}

\section{Group}

Age (years) $\geq 65$ Age (years) $<65$

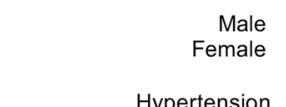

Hypertension No Hypertension

Smoking No Smoking

$$
\begin{array}{r}
\text { CAD } \\
\text { No CAD } \\
\text { PAD } \\
\text { no PAD }
\end{array}
$$

$\mathrm{LDL}>100 \mathrm{mg} / \mathrm{dL}$ $\mathrm{LDL} \leq 100 \mathrm{mg} / \mathrm{dL}$

TRGs $>150 \mathrm{mg} / \mathrm{dL}$ TRGs $\leq 150 \mathrm{mg} / \mathrm{dL}$

eGFR $\geq 60 \mathrm{~mL} / \mathrm{min} / 1.72 \mathrm{~m}^{2}$ eGFR $<60 \mathrm{~mL} / \mathrm{min} / 1.72 \mathrm{~m}^{2}$ $p$ value for interaction

0.10

0.89

0.07

0.14

0.003

0.04

0.02

0.15

0.50

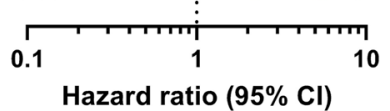

Fig. 3 Forest plot of the hazard ratio for A MACE in 3 years and $\mathbf{B}$ 5-year all-cause mortality risk comparing first and fourth quartiles of hs-cTnT levels in different groups as indicated. The 5-95\% confidence interval is indicated by line length. P value for trend was calculated by Cochran-Armitage and Jonckheere-Terpstra tests of trend to compare baseline characteristics across increasing quartiles of hs-cTnT for categorical and continuous variables, respectively. CAD coronary artery disease, eGFR estimated glomerular filtration rate, LDL low density lipoprotein cholesterol, $P A D$ peripheral artery disease, TRGs triglycerides
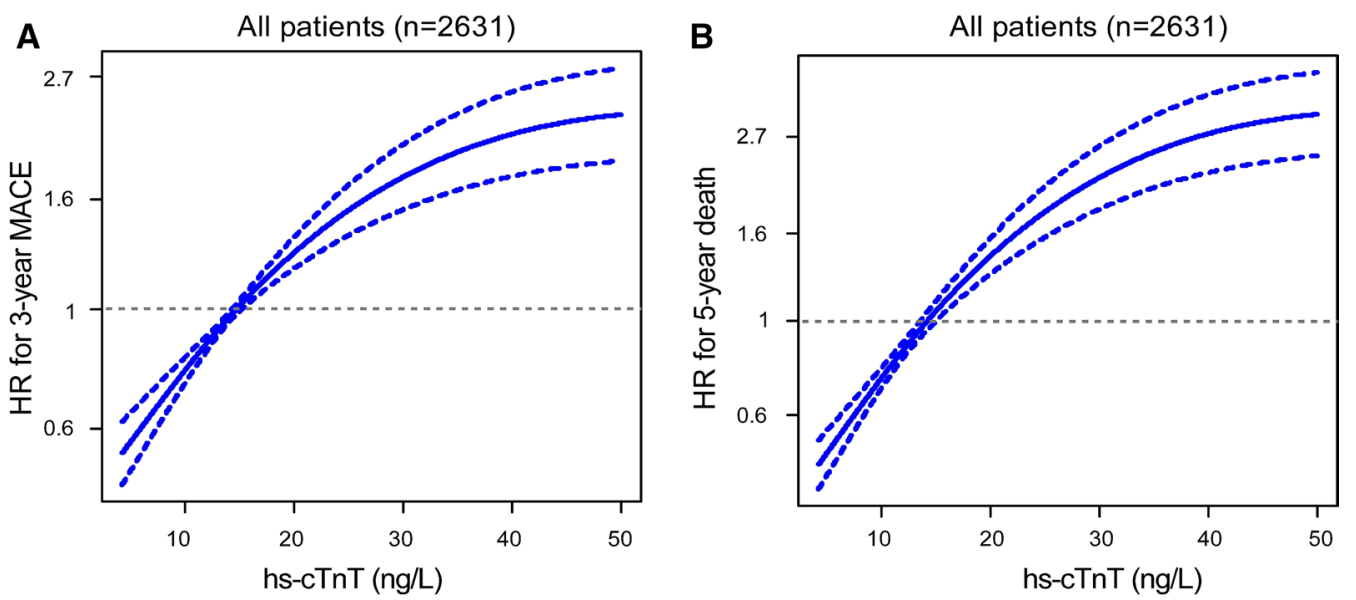

Fig. 4 Cubic spline curves of the hazard ration (HR) for $\mathbf{A}$ major adverse cardiac events (MACE, death, nonfatal myocardial infarction, and stroke) at 3 years and $\mathbf{B}$ death at 5 years with hs-cTnT levels 
performed and more broadly available what makes it a more attractive diagnostic tool.

Once CVD is present in a prediabetic environment, using prediabetes as a stand-alone prognostic marker for CVD risk yielded conflicting results in stable [10,11] or acute $[32,33]$ patients and in this setting prediabetes status alone fails to universally predict outcomes. On one hand, this might be explained by clustering of prediabetes state with other glycemic CVD risk factors [4, 34]. On the other hand, limited data in prediabetic patients and inconsistent clinical studies that used different classifications and cutoffs for prediabetes preclude general conclusions about event risk. Yet, the majority of patients with CVD shows an abnormal glucose metabolism [35] and novel non-glycemic biomarkers are needed for risk stratification to guide secondary prevention of patients with prediabetes. Our findings suggest that assessment of hscTnT can help risk stratify prediabetic subjects to guide secondary preventive efforts.

Use of next generation hs-cTnT assays greatly improved the diagnosis of acute coronary syndromes, and has been increasingly available in the acute clinical setting. Interestingly, in patients in whom an acute myocardial infarction has been ruled out in a binary approach, hs-cTnT is a strong predictor for future risk of myocardial infarction and mortality, indicating prognostic value on a continuous scale [36]. Due to their higher sensitivities, the 5th generation hs-cTnT assays allow detection of trace levels of cardiac troponins even on a general population level where it was found to be associated with heart disease and mortality risk [37]. This led to exploration of hs$\mathrm{cTnT}$ as a prognostic biomarker in various stable cardiovascular phenotypes, such as CVD [12], heart failure [13] or hypertrophic cardiomyopathy [38]. Our study has the potential to expand the prognostic utility of hs-cTnT from the general population [6] or individuals with diabetes [14] to stable cardiac patients with prediabetes.

Although the mechanisms leading to troponin leakage with detectable amount of hs-cTnT in the plasma are not completely understood, chronic myocardial stress, cardiomyocyte injury and isolated subendocardial ischemia have been proposed [39]. Although CVD was more prevalent with increasing levels of hs-cTnT in our patient cohort, adjustment for CVD did not abrogate the association of hs-cTnT with event risk (Additional file 1: Tables S1-S3) and even in the absence of CVD we found SMN portends event risk (Fig. 2) suggesting other mechanisms involved.

Other factors that are associated with elevated hscTnT levels in general populations were age, gender, low density lipoprotein cholesterol and blood pressure [40, 41], which were included into our multivariate analysis, along with other traditional CVD risk factors and kidney function. We also observed higher levels of hsCRP with increasing hs-cTnT levels. In a recent study, Lucci et al. prospectively followed 2064 patients with acute myocardial infarction and found that hsCRP levels predicted mortality and were correlated with hs-cTnI both in patients with and without diabetes [42]. Although the link between CRP and SMN in stable patients warrants further investigation adjusting for hsCRP did not change the association of hs-cTnT in our prediabetic cohort (Additional file 1: Tables S1-S3).

In a recent pooled analysis on the population level, prediabetes status was associated with a higher lifetime risk for heart failure in middle-aged white adults and black women [43]. Another study found sex-specific maladaptive left ventricular changes as glucose tolerance worsened from normal to prediabetes [44]. Hs-cTnT levels $\geq 6 \mathrm{ng} / \mathrm{L}$ were recently added to a biomarker score for heart failure risk stratification in subject with diabetes and prediabetes [45]. Interestingly, adjustment for LVEF did not change association of hscTnT with event risk in our cohort (Additional file 1: Tables S1-S3).

Generally, the 99th percentile of a healthy reference population defined by the manufacturer may identify individuals with elevated hs-cTnT levels. Although in our stable prediabetes cohort a myocardial infarction has been ruled out, we observed that a significant proportion of the subjects in our cohort exceeded the reported 99th percentile of $14 \mathrm{ng} / \mathrm{L}$ for our assay. Our data highlights that prediabetes in the presence of CVD risk factors is associated with robust levels of plasma hs-cTnT. However, current reference ranges for hscTnT have been optimized for diagnosing acute coronary syndromes and likely need to be better defined for individual populations [46].

Our data suggest that use of hs-cTnT for risk stratification in stable prediabetes subjects undergoing elective diagnostic cardiac evaluations provides an additional tool to help identify the subset of subjects who are at a "high risk equivalent", and may thus benefit from more aggressive modifiable risk reduction strategies. Including nonglycemic biomarkers into the risk assessment for prediabetic patients with CVD risk factors may help to overcome the limitations of using prediabetes status as a standalone measure to predict CVD outcomes. Further studies to better understand the metabolic alterations that occur concurrently with changes in glycemic control that led to the classification of subjects as "prediabetic" may prove helpful in further expanding upon the preventive strategies to try and mitigate the increased risks observed with hs-cTnT elevation in this cohort. 


\section{Study limitations}

The present study has several limitations. Measurement of hs-cTnT was only performed once at time of enrolment, during angiographic evaluation of the stable cohort. Whether serial measures provide enhanced prognostic value for incident CVD risks, or would begin to correlate with glucose or HbA1C levels is unknown. We also did not include oral glucose tolerance testing, which could have caused some misclassifications of patients. It should be noted, however, that the definition of prediabetes used was in accordance with the ADA guidelines and represents the general clinical practice that prefers fasting glucose and HbA1c over the less convenient and costlier oral glucose tolerance test.

\section{Conclusions}

Our findings provide strong evidence detectable levels of hs-cTnT, an indicator of SMN, is prevalent in patients with prediabetes undergoing elective diagnostic cardiovascular risk evaluation. Moreover, hs-cTnT levels in this cohort were independently associated with both CVD event risk, and long term (5-year) mortality risks among all subjects, as well as among the subsets with documented CVD (secondary prevention) and without CVD (primary prevention). In subjects with prediabetes and risk factors (that represent a large population), hs-cTnT may help to stratify risk and guide preventive efforts to use healthcare resources more efficiently. The strong clinical prognostic utility of hs-cTnT suggests its incorporation into current practice guidelines for prediabetic subjects undergoing cardiac evaluations should be further studied.

\begin{abstract}
Abbreviations
CAD: Coronary artery disease; CVD: Cardiovascular disease; eGFR: Estimated glomerular filtration rate; IFG: Impaired fasting glucose; IGT: Impaired glucose tolerance; HbA1c: Glycated hemoglobin A1c; hsCRP: High-sensitivity C-reactive protein; hs-cTnT: High sensitivity cardiac troponin T; MACE: Major adverse cardiac events; OGTT: Oral glucose tolerance test.
\end{abstract}

\section{Supplementary Information}

The online version contains supplementary material available at https://doi. org/10.1186/s12933-021-01365-9.

Additional file 1: Table S1. Coronary angiography findings and rates of revascularization within 30 days following procedure across hs-cTnT quartiles. Table S2A. Major adverse cardiac event (MACE) risk according to quartiles of hs-cTnT with additional adjustments in the entire prediabetes cohort. Table S2B. All-cause mortality according to quartiles of hs-cTnT with additional adjustments in the entire prediabetes cohort. Table S3A. Major adverse cardiac event (MACE) risk according to quartiles of hs-cTnT with additional adjustments in secondary prevention subjects. Table S3B. All-cause mortality according to quartiles of hs-cTnT with additional adjustments in secondary prevention subjects. Table S4A. Major adverse cardiac event (MACE) risk according to pooled quartiles 1, 2 and 3 vs. quartile 4 of hs-cTnT with additional adjustments in primary prevention subjects. Table S4B. All-cause mortality risk according to pooled quartiles 1,2 and 3 vs. quartile 4 of hs-cTnT with additional adjustments in primary prevention subjects. Table S5A. Major adverse cardiac event (MACE) risk according to quartiles of hs-cTnT with additional adjustments in the entire prediabetes cohort excluding those who underwent coronary revascularization within 30 days after angiography. Table S5B. All-cause mortality according to quartiles of hs-cTnT with additional adjustments in the entire prediabetes cohort excluding those who underwent coronary revascularization within 30 days after angiography.

\section{Acknowledgements}

Not applicable.

\section{Authors' contributions}

MW wrote the manuscript. YF performed the statistical analyses. SLH and WHWT conceived study design and procured biospecimens and funding support. All authors critically reviewed the manuscript. All authors read and approved the final manuscript.

\section{Funding}

This work is supported by grants from the NIH and Office of Dietary Supplements (P01HL147823, R01HL103866) and the Deutsche Forschungsgemeinschaft (WI 5229/1-1). Research hs-cTnT and hsCRP reagents were provided by Roche Diagnostics.

\section{Availability of data and materials}

The authors do not have written consent from study participants to make data and materials available for public access.

\section{Declarations}

Ethics approval and consent to participate

The study complied with the principles of Good Clinical Practice rules. All participants gave written informed consent to a protocol that was approved by the Cleveland Clinic Institutional Review Board.

\section{Consent for publication}

All authors have read the final version and agreed to publish the manuscript.

\section{Competing interests}

Dr. Hazen reports being named as co-inventor on pending and issued patents held by the Cleveland Clinic relating to cardiovascular diagnostics and therapeutics. Dr. Hazen also reports being a paid consultant for Procter \& Gamble, having received research funds from Procter \& Gamble, and Roche Diagnostics, and being eligible to receive royalty payments for inventions or discoveries related to cardiovascular diagnostics or therapeutics from Cleveland HeartLab, a fully owned subsidiary of Quest Diagnostics, and Procter \& Gamble. Dr. Tang has served as a paid consultant for Sequana Medical AG, Owkin Inc, Relypsa Inc, Cardiol Therapeutics Inc, preCARDIA Inc, Genomics plc, and received honoraria from Springer Nature and American Board of Internal Medicine, all unrelated to the present topic. The other authors have reported that they have no relationships relevant to the contents of this paper to disclose.

\section{Author details}

${ }^{1}$ Department of Cardiovascular \& Metabolic Sciences, Lerner Research Institute, Cleveland Clinic, Cleveland, OH, USA. ${ }^{2}$ Department of Mathematics, Cleveland State University, Cleveland, $\mathrm{OH}$, USA. ${ }^{3}$ Department of Cardiovascular Medicine, Heart, Vascular and Thoracic Institute, Cleveland Clinic, 9500 Euclid Avenue, Desk J3-4, Cleveland, OH 44195, USA.

Received: 23 June 2021 Accepted: 15 August 2021

Published online: 21 August 2021 


\section{References}

1. Classification and Diagnosis of Diabetes. Standards of medical care in diabetes-2019. Diabetes Care. 2019:42(Suppl 1):S13-28.

2. Centers for Disease Control and Prevention. National diabetes statistics report A, GA: Centers for Disease Control and Prevention, US Department of Health and Human Services; 2017

3. De Caterina R, Madonna R. Impaired fasting plasma glucose and long-term cardiovascular risk: still a foggy relationship. Eur Heart J. 2010:31(10):1159-62.

4. Schöttker B, Müller H, Rothenbacher D, Brenner $H$. Fasting plasma glucose and $\mathrm{HbA} 1 \mathrm{C}$ in cardiovascular risk prediction: a sex-specific comparison in individuals without diabetes mellitus. Diabetologia. 2013;56(1):92-100.

5. Gordon-Dseagu VLZ, Mindell JS, Steptoe A, Moody A, Wardle J, Demakakos P, et al. Impaired glucose metabolism among those with and without diagnosed diabetes and mortality: a cohort study using health survey for England data. PLoS ONE. 2015;10(3):e0119882.

6. Selvin E, Lazo M, Chen Y, Shen L, Rubin J, McEvoy JW, et al. Diabetes mellitus, prediabetes, and incidence of subclinical myocardial damage. Circulation. 2014;130(16):1374-82.

7. Doi Y, Ninomiya T, Hata J, Fukuhara M, Yonemoto K, Iwase M, et al. Impact of glucose tolerance status on development of ischemic stroke and coronary heart disease in a general Japanese population: the Hisayama study. Stroke. 2010;41(2):203-9.

8. de Ritter R, Sep SJS, van der Kallen CJH, van Greevenbroek MMJ, de Jong $\mathrm{M}, \operatorname{Vos} \mathrm{RC}$, et al. Sex differences in the association of prediabetes and type 2 diabetes with microvascular complications and function: the Maastricht study. Cardiovasc Diabetol. 2021;20(1):102.

9. Åkerblom A, Wojdyla D, Steg PG, Wallentin L, James SK, Budaj A, et al. Prevalence and relevance of abnormal glucose metabolism in acute coronary syndromes: insights from the PLATelet inhibition and patient outcomes (PLATO) trial. J Thromb Thrombolysis. 2019:48(4):563-9.

10. Kiviniemi AM, Lepojarvi ES, Tulppo MP, Piira OP, Kentta TV, Perkiomaki JS, et al. Prediabetes and risk for cardiac death among patients with coronary artery disease: the ARTEMIS study. Diabetes Care. 2019;42(7):1319-25.

11. Shahim B, De Bacquer D, De Backer G, Gyberg V, Kotseva K, Mellbin L, et al. The prognostic value of fasting plasma glucose, two-hour postload glucose, and $\mathrm{HbA} 1 \mathrm{c}$ in patients with coronary artery disease: a report from EUROASPIRE IV: a survey from the European society of cardiology. Diabetes Care. 2017;40(9):1233-40

12. Tang WH, Wu Y, Nicholls SJ, Brennan DM, Pepoy M, Mann S, et al. Subclinical myocardial necrosis and cardiovascular risk in stable patients undergoing elective cardiac evaluation. Arterioscler Thromb Vasc Biol. 2010;30(3):634-40.

13. Grodin JL, Neale S, Wu Y, Hazen SL, Tang WH. Prognostic comparison of different sensitivity cardiac troponin assays in stable heart failure. Am J Med. 2015;128(3):276-82.

14. Tang WH, Wu Y, Britt EB Jr, lqbal N, Hazen SL. Detectable subclinical myocardial necrosis is associated with cardiovascular risk in stable patients with diabetes. Diabetes Care. 2013:36(5):1126-31.

15. Rubin J, Matsushita K, Ballantyne CM, Hoogeveen R, Coresh J, Selvin E. Chronic hyperglycemia and subclinical myocardial injury. J Am Coll Cardiol. 2012;59(5):484-9.

16. Stevens LA, Schmid CH, Greene T, Zhang Y, Beck GJ, Froissart M, et al. Comparative performance of the CKD epidemiology collaboration (CKD$\mathrm{EPI}$ ) and the modification of diet in renal disease (MDRD) study equations for estimating GFR levels above $60 \mathrm{~mL} / \mathrm{min} / 1.73 \mathrm{~m}^{2}$. Am J Kidney Dis. 2010;56(3):486-95.

17. Zhou Z, Sun B, Huang S, Zhu C, Bian M. Glycemic variability: adverse clinical outcomes and how to improve it? Cardiovasc Diabetol. 2020;19(1):102.

18. Hartge MM, Unger T, Kintscher U. The endothelium and vascular inflammation in diabetes. Diabetes Vasc Dis Res. 2007:4(2):84-8.

19. Witkowski M, Tabaraie T, Steffens D, Friebel J, Dörner A, Skurk C, et al. MicroRNA-19a contributes to the epigenetic regulation of tissue factor in diabetes. Cardiovasc Diabetol. 2018;17(1):34.

20. Paolisso P, Foà A, Bergamaschi L, Donati F, Fabrizio M, Chiti C, et al. Hyperglycemia, inflammatory response and infarct size in obstructive acute myocardial infarction and MINOCA. Cardiovasc Diabetol. 2021;20(1):33.

21. Kakouros N, Rade JJ, Kourliouros A, Resar JR. Platelet function in patients with diabetes mellitus: from a theoretical to a practical perspective. Int J Endocrinol. 2011. https://doi.org/10.1155/2011/742719.
22. Schuette C, Steffens D, Witkowski M, Stellbaum C, Bobbert P, Schultheis $\mathrm{HP}$, et al. The effect of clopidogrel on platelet activity in patients with and without type-2 diabetes mellitus: a comparative study. Cardiovasc Diabetol. 2015;14:15.

23. Kario K, Matsuo T, Kobayashi H, Matsuo M, Sakata T, Miyata T. Activation of tissue factor-induced coagulation and endothelial cell dysfunction in non-insulin-dependent diabetic patients with microalbuminuria. Arterioscler Thromb Vasc Biol. 1995;15(8):1114-20.

24. Witkowski M, Witkowski M, Saffarzadeh M, Friebel J, Tabaraie T, Ta Bao $\mathrm{L}$, et al. Vascular miR-181b controls tissue factor-dependent thrombogenicity and inflammation in type 2 diabetes. Cardiovasc Diabetol. 2020;19(1):20

25. Witkowski M, Friebel J, Tabaraie T, Grabitz S, Dörner A, Taghipour L, et al. Metformin is associated with reduced tissue factor procoagulant activity in patients with poorly controlled diabetes. Cardiovasc Drugs Ther. 2021:35(4):809-13.

26. Huang Y, Cai X, Mai W, Li M, Hu Y. Association between prediabetes and risk of cardiovascular disease and all cause mortality: systematic review and meta-analysis. BMJ. 2016;355:i5953.

27. Tai ES, Goh SY, Lee JJ, Wong MS, Heng D, Hughes K, et al. Lowering the criterion for impaired fasting glucose: impact on disease prevalence and associated risk of diabetes and ischemic heart disease. Diabetes Care. 2004;27(7):1728-34

28. Nguyen BM, Lin KW, Mishori R. Public health implications of overscreening for carotid artery stenosis, prediabetes, and thyroid cancer. Public Health Rev. 2018;39:18.

29. Piller C. Dubious diagnosis. Science. 2019:363(6431):1026-31.

30. Kwong RY, Sattar H, Wu H, Vorobiof G, Gandla V, Steel K, et al. Incidence and prognostic implication of unrecognized myocardial scar characterized by cardiac magnetic resonance in diabetic patients without clinica evidence of myocardial infarction. Circulation. 2008;118(10):1011-20.

31. Ohyama Y, Volpe GJ, Lima JAC. Subclinical myocardial disease in heart failure detected by CMR. Curr Cardiovasc Imaging Rep. 2014;7:9269.

32. Sinnaeve PR, Steg PG, Fox KA, Van de Werf F, Montalescot G, Granger CB, et al. Association of elevated fasting glucose with increased short-term and 6-month mortality in ST-segment elevation and non-ST-segment elevation acute coronary syndromes: the Global Registry of Acute Coronary Events. Arch Intern Med. 2009:169(4):402-9.

33. Giraldez RR, Clare RM, Lopes RD, Dalby AJ, Prabhakaran D, Brogan GX Jr, et al. Prevalence and clinical outcomes of undiagnosed diabetes mellitus and prediabetes among patients with high-risk non-ST-segment elevation acute coronary syndrome. Am Heart J. 2013;165(6):918-25.e2.

34. Vistisen D, Witte DR, Brunner EJ, Kivimaki M, Tabak A, Jorgensen ME, et al. Risk of cardiovascular disease and death in individuals with prediabetes defined by different criteria: the Whitehall II study. Diabetes Care. 2018;41(4):899-906.

35. Bartnik M, Malmberg K, Norhammar A, Tenerz A, Ohrvik J, Ryden L. Newly detected abnormal glucose tolerance: an important predictor of long-term outcome after myocardial infarction. Eur Heart J. 2004;25(22):1990-7

36. Neumann JT, Twerenbold R, Ojeda F, Sorensen NA, Chapman AR, Shah ASV, et al. Application of high-sensitivity troponin in suspected myocardial infarction. N Engl J Med. 2019;380(26):2529-40.

37. de Lemos JA, Drazner MH, Omland T, Ayers CR, Khera A, Rohatgi A, et al. Association of troponin T detected with a highly sensitive assay and cardiac structure and mortality risk in the general population. JAMA. 2010;304(22):2503-12.

38. Kubo T, Kitaoka H, Okawa M, Yamanaka S, Hirota T, Baba Y, et al. Combined measurements of cardiac troponin I and brain natriuretic peptide are useful for predicting adverse outcomes in hypertrophic cardiomyopathy. Circ J. 2011;75(4):919-26.

39. Feng J, Schaus BJ, Fallavollita JA, Lee TC, Canty JM Jr. Preload induces troponin I degradation independently of myocardial ischemia. Circulation. 2001:103(16):2035-7.

40. Daniels LB, Laughlin GA, Clopton P, Maisel AS, Barrett-Connor E. Minimally elevated cardiac troponin $\mathrm{T}$ and elevated $\mathrm{N}$-terminal pro-B-type natriuretic peptide predict mortality in older adults: results from the Rancho Bernardo study. J Am Coll Cardiol. 2008;52(6):450-9.

41. Wallace TW, Abdullah SM, Drazner MH, Das SR, Khera A, McGuire DK, et al. Prevalence and determinants of troponin T elevation in the general population. Circulation. 2006;113(16):1958-65. 
42. Lucci C, Cosentino N, Genovese S, Campodonico J, Milazzo V, De Metrio $\mathrm{M}$, et al. Prognostic impact of admission high-sensitivity C-reactive protein in acute myocardial infarction patients with and without diabetes mellitus. Cardiovasc Diabetol. 2020;19(1):183.

43. Sinha A, Ning H, Ahmad FS, Bancks MP, Carnethon MR, O'Brien MJ, et al. Association of fasting glucose with lifetime risk of incident heart failure: the Lifetime Risk Pooling Project. Cardiovasc Diabetol. 2021;20(1):66.

44. Succurro E, Miceli S, Fiorentino TV, Sciacqua A, Perticone M, Andreozzi $F$, et al. Sex-specific differences in left ventricular mass and myocardial energetic efficiency in non-diabetic, pre-diabetic and newly diagnosed type 2 diabetic subjects. Cardiovasc Diabetol. 2021;20(1):60
45. Pandey A, Vaduganathan M, Patel KV, Ayers C, Ballantyne CM, Kosiborod $M N$, et al. Biomarker-based risk prediction of incident heart failure in prediabetes and diabetes. JACC Heart Fail. 2021;9(3):215-23.

46. Gore MO, Seliger SL, Defilippi CR, Nambi V, Christenson RH, Hashim IA, et al. Age- and sex-dependent upper reference limits for the high-sensitivity cardiac troponin T assay. J Am Coll Cardiol. 2014;63(14):1441-8.

\section{Publisher's Note}

Springer Nature remains neutral with regard to jurisdictional claims in published maps and institutional affiliations.
Ready to submit your research? Choose BMC and benefit from:

- fast, convenient online submission

- thorough peer review by experienced researchers in your field

- rapid publication on acceptance

- support for research data, including large and complex data types

- gold Open Access which fosters wider collaboration and increased citations

- maximum visibility for your research: over $100 \mathrm{M}$ website views per year

At BMC, research is always in progress.

Learn more biomedcentral.com/submissions 